\title{
Dagaa (Rastrinoebola argentea) protein hydrolysate as a nitrogen source in microbial culture media
}

\author{
Katherine Pere ${ }^{1}$, Betty Mbatia $^{2}$, Edward Muge $^{1}$, Vitalis W. Wekesa ${ }^{3 *}$ \\ ${ }^{1}$ Department of Biochemistry, University of Nairobi, P.O. Box 30197-00100, Nairobi, Kenya. \\ ${ }^{2}$ School of Pharmacy, United States International University, P.O Box 14634-00800,, Nairobi, Kenya. \\ ${ }^{3}$ Flamingo Horticulture Kenya Limited, Biorationals Unit, P.O Box 1927, Naivasha, 20117, Kenya.
}

\section{ARTICLE INFO}

Article history:

Received on: 17/03/2017

Accepted on: 15/04/2017

Available online: 19/06/2017

Key words:

Dagaa protein hydrolysate,

Culture media, Microorganisms.

\begin{abstract}
Dagaa is a small pelagic fish found in Lake Victoria. It is used as a nutrient source in animal feeds and human consumption. Utilization of fish protein hydrolysate as a nutrient in culture media has been explored in several fish species and dagaa protein hydrolysate (DPH) can also be a candidate due to its rich protein and lipid content. Potential of DPH as a nitrogenous source in microbial growth media was assayed using the following bacteria; Escherichia coli, Pseudomonas aeroginosa, Bacillus subtilis and Rhodobacter capsulatus and two fungi, Metarhizium anisopliae and Beauveria bassiana. Cell growth was evaluated using turbidity and biomass in liquid cultures. DPH formulated media produced similar cell growth when compared to positive controls made up of Luria Bertani (LB) for bacteria and Sabouraud's dextrose broth (SDB) for fungi. This indicates that formulated DPH media can be considered as an alternative media for microbial culture.
\end{abstract}

\section{INTRODUCTION}

Culture of microorganisms is a very important part of research especially when used in molecular biology and biotechnology and is also important in foundational and basic diagnostic methods [1]. Current commercial culture media in the market contain at least a nitrogen source, a carbohydrate source and other nutritional components. The nitrogenous source is usually the most expensive in preparation of culture media [2]. There is need to prepare culture media from protein sources that are easily available and efficient in terms of the nitrogenous content they will supply such as fish [3]. Peptone being one of the nitrogenous sources of microbial media is derived primarily from bovine or porcine origins such as meat, internal organs, gelatin and milk [4]. Plant sources such as soybean extract can also be used as nitrogenous sources for microbial media [5]. Due to outbreaks of bovine and porcine diseases, use of peptones of nonmeat origin is becoming increasingly popular and thus media with peptone derived from vegetables and yeast is currently available on the market [4]. Muslims and Jews might also not be

\footnotetext{
* Corresponding Author

Vitalis W Wekesa, Flamingo Horticulture Kenya Limited, Biorationals Unit, P.O Box 1927, Naivasha, 20117, Kenya. Email:vwwekesa@gmail.com
}

comfortable using media containing porcine extracts on religious grounds. In addition, several underutilized fish species and fish byproducts have been used to prepare fish peptone. The formulated fish peptone media has been shown to possess similar yields of microbes in comparison with standard media [6]. Peptone prepared from silver carp (Hypophthalmichthys molitrix) head using enzyme alcalase was found to have a protein concentration of $20.7 \%$ [7]. The growth of Vibrio anguillarum in silver carp head peptone was not significantly $(\mathrm{p}>0.05)$ different from the growth of this bacterium in standard peptone media [7]. Alcalase hydrolysate from silver carp filleting had a protein content of $20.7 \%$ and has also been shown to perform better than tryptic soy broth (TSB) media in the growth of Staphylococcus aureus [8]. Choice of enzyme for the preparation of fish hydrolysate is critical in determining the performance of the microbial media. For example, hydrolysis of silver carp with trypsin yielded a protein hydrolysate that performed less than the standard media [8]. This was in contrast with results obtained using alcalase hydrolysate. This difference could be attributed to the fact that alcalase is generally a better and effective proteinase than papain, flavourzyme and trypsin $[9,10]$. Currently in Kenya, lake sardine/silver cyprinid locally known as dagaa (Rastrineobola argentea) accounts for the second largest fish catch at Lake Victoria [11, 12]. It is relatively inexpensive and available as compared to nile perch (Lates niloticus) [13]. 
It has large post-harvest losses of up to $50 \%$ in the rainy season [13]. Proximate studies carried out on dagaa have shown that it is rich in protein (19.1-21.7\%) [14]. This makes it a good candidate for a nitrogenous source of culture media. The aim of this work was to investigate the potential of dagaa protein hydrolysate as a nitrogen source in culture media.

\section{MATERIALS AND METHODS}

\subsection{Preparation of Dagaa Protein hydrolysate}

The dagaa used in the study was bought from Nairobi city market. Fish hydrolysate was prepared by use of a commercial exogenous protease alcalase ${ }^{\circledR}$. Alcalase is a serine protease enzyme from Bacillus licheniformis (Sigma Aldrich, USA). The DFH was prepared using the protocol as described [14]. The DFH was then mixed with hexane (Sigma Aldrich, USA) to extract lipids to give DPH which is composed mostly of peptides from the hydrolyzed dagaa. DPH was then transferred into $15 \mathrm{ml}$ falcon tubes and centrifuged using a refrigerated centrifuge (Hanil Science Industrial, Korea) at $12000 \mathrm{rpm}$ for 20 minutes at $4^{\circ} \mathrm{C}$. The DPH was then stored at $-20^{\circ} \mathrm{C}$ until time of use.

\subsection{Preparation of microbial media}

\subsubsection{Preparation of Dagaa protein hydrolysate formulated media (DPH-FM for bacterial growth}

Protein content of LB the standard media and DPH were determined using Biuret's protein assay [15]. The DPH-FM was then equated in protein content to the standard media LB. The DPH-FM was made up of $10 \mathrm{~g}$ sodium chloride $(\mathrm{NaCl})$ (Sigma Aldrich, USA), $300 \mathrm{ml}$ of DPH and $5 \mathrm{~g}$ of Yeast Extract (Sigma Aldrich, USA) per liter. The $\mathrm{NaCl}$ supplemented Sodium mineral which was in very minute concentrations in the DPH. The media was autoclaved at $121^{\circ} \mathrm{C}$ at $15 \mathrm{psi}$ for $15 \mathrm{~min}$ in autoclave (Tuttnauer, USA) and cooled before use.

\subsubsection{Preparation of Dagaa protein hydrolysate formulated media (DPH-Dextrose) for fungal growth}

The protein content of both the standard SDB media as well as the DPH-Dextrose was determined using Biuret's protein assay. The protein content of the DPH-Dextrose media was then equated to that of SDB media. The formulated DPH-Dextrose media for fungi was constituted as follows; $300 \mathrm{ml}$ of DPH and $40 \mathrm{~g}$ of dextrose (Sigma Aldrich, USA) per liter with dextrose being added as DPH did not contain any. Since the fungi used in this work were aciduric, the $\mathrm{pH}$ of the media was adjusted to $5.5 \mathrm{using}$ hydrochloric acid. This was then autoclaved at $121^{\circ} \mathrm{C}, 15 \mathrm{psi}$ for $15 \mathrm{~min}$ in an autoclave.

\subsubsection{Preparation of standard media for bacterial growth and for fungal growth.}

To prepare LB media for bacterial growth, the following components were dissolved in $1 \mathrm{~L}$ of distilled water; $5 \mathrm{~g}$ of yeast extract, $10 \mathrm{~g}$ of tryptone (Sigma Aldrich, USA) and $10 \mathrm{~g}$ of $\mathrm{NaCl}$
[16]. The contents were autoclaved at $121^{\circ} \mathrm{C}$ at $15 \mathrm{psi}$ for $15 \mathrm{~min}$ in an autoclave and cooled before use.

SDB media for fungal growth was prepared by dissolving the following components in $1 \mathrm{~L}$ of distilled water; $10 \mathrm{~g}$ of mycological peptone (Sigma Aldrich, USA) and 40g of dextrose [17]. The contents were autoclaved at $121^{\circ} \mathrm{C}$ at $15 \mathrm{psi}$ for $15 \mathrm{~min}$ in an autoclave and cooled before use.

\subsection{Microbial culturing to investigate the potential of DPH as a nitrogen source in culture media}

\subsubsection{Growing bacterial cultures to estimate cell mass}

Four bacterial species were cultured: Escherichia coli, Bacillus subtilis, Pseudomonas aeruginosa and Rhodobacter capsulatus. All these microorganisms were acquired from the laboratory cultures of Jomo Kenyatta University of Agriculture and Technology. To grow the bacterial cultures of E. coli, B. subtilis, $P$. aeruginosa and $R$. capsulatus, LB media was used as the standard while DPH-FM served as the experimental media. For the growth of $R$. capsulatus (a halophytic bacterium), both the standard and formulated media were adjusted to $\mathrm{pH} 10$ and 5\% $\mathrm{NaCl}$ concentration. Media was prepared and placed in $250 \mathrm{ml}$ Erlenmeyer flasks in amounts of $100 \mathrm{ml}$ and $200 \mu \mathrm{l}$ of the bacteria inoculated separately in different flasks under a biological safety cabinet level 3 (Heraeus, Germany). The microorganisms were then placed in an incubated orbital shaker (Gerhardt, Germany) at the speed of $120 \mathrm{rpm}$ and temperature of $37^{\circ} \mathrm{C}$. Samples were picked at different intervals of $0,0.5,2,5,7,10,25$ and $26 \mathrm{hrs}$ for optical density (OD) and biomass to estimate the growth titers. The values recorded were then used to prepare growth curves for each of the microorganisms.

\subsubsection{Growing of fungal cultures to estimate cell mass}

The following two fungi were cultured in this study; Metarhizium anisopliae and Beauveria bassiana. The two fungi are used as bio-pesticides and both of them were grown on SDB standard media and formulated DPH-Dextrose media. Volumes of $100 \mathrm{ml}$ of each media were prepared and placed in $250 \mathrm{ml}$ Erlenmeyer flasks and $200 \mu \mathrm{l}$ of each fungi inoculated separately under a biological safety cabinet level 3. The samples were then placed in an incubated orbital shaker at a speed of $180 \mathrm{rpm}$ and temperature of $25^{\circ} \mathrm{C}$. The samples $(5 \mathrm{ml})$ were then picked at time intervals of $0 \mathrm{hr}$ and after every 2 days during 21 days of growth for optical density and biomass to estimate the growth titers. The values recorded were then used to prepare growth curves for each of the microorganisms.

\subsection{Statistical analysis.}

Experimental data were analysed by one-way analysis of variance (ANOVA) using statistical software SPSS version 19. Treatment means were separated by Turkey's multiple comparison test at $\alpha=0.05$. Media were compared based with respect to their effect on growth and biomass of individual microorganisms. All 
conclusions are based on experiments that were repeated in triplicates over time to ensure reproducibility of results.

\section{RESULTS AND DISCUSSION}

A protein hydrolysate prepared from neglected dagaa fish was defatted and its protein content estimated to be $2.6 \mathrm{mg} / \mathrm{ml}$. This indicates that the experimental fish contains high amount of protein and apart from being used as low grade fish meal, its use in preparation of microbial culture media might give fish hydrolysates a value addition [3].

With most standard microbial media consisting mostly of digested proteins from bovine or porcine origin the upcoming use of fish hydrolysate is a new avenue of obtaining proteins from a source that is less likely to be contaminated by diseases [4]. In this study dagaa fish hydrolysate only substituted for the nitrogenous part of the media with the formulated media retaining yeast extract and dextrose as well as sodium chloride as a mineral content that were also present in the standard media used.

Growth curves of the bacterial (E. coli, B. subtilis, $P$. aeruginosa and $R$. capsulatus) and fungal species (M. anisopliae and $B$. bassiana) by optical density in both the formulated media and standard media are shown in figures $1,2,3,4,5$ and 6 respectively. The growth curves indicated almost similar growth patterns for bacterial and fungal species in both the DPH-FM and in the standard media.

The stages of bacterial and fungal growth differ depending on the growth of microbes in the different media as indicated.For E. coli, the lag phase in DPH-FM was observed to be longer than in LB (Figure 1), similarly, it took 10 hrs to obtain an optical density of 1.5 in LB while it took approximately $20 \mathrm{hrs}$ to obtain the same optical density in DPH-FM media. After $10 \mathrm{hrs}$, E. coli growth had reached plateau stage in LB while in DPH-FM, the growth was still at exponential stage up to $26 \mathrm{hrs}$. A longer lag phase in DPH-FM could indicate that $E$. coli require more time in this formulated media to adapt to the new environment as compared to LB media [18].

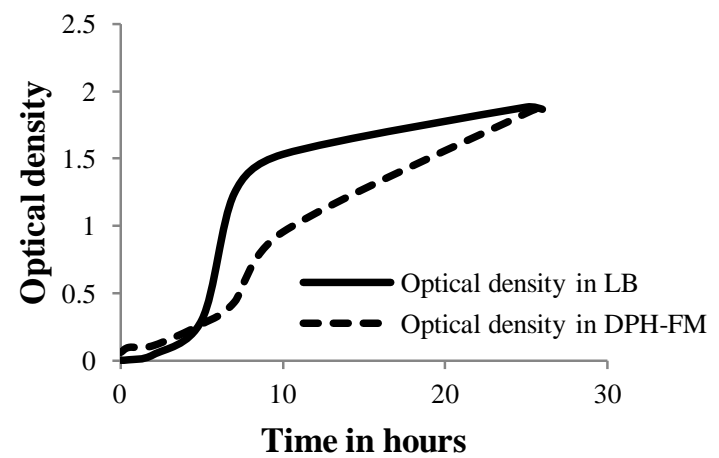

Fig. 1: Growth pattern of Escherichia coli in LB and DPH-FM media.

E. coli was found to have an almost similar biomass in both DPH-FM at $23.4 \mathrm{~g} / \mathrm{l}$ and LB media at $23.6 \mathrm{~g} / \mathrm{l}$ after $26 \mathrm{hrs}$ of growth (Table 1). This is an indication that the growth was not very different in both media though the stages of growth seemed to be different in the two media. On the growth of $E$. coli as measured by optical density, the lag phase of $E$. coli growth was found to be slow and took about $5 \mathrm{hrs}$ to achieve log phase in both DPH-FM and in LB media. The slow lag phase could be attributed to factors such as the time needed for the microbe to recover from physical damage as well as shock in the transfer/inoculation process. This could also be attributed to time required for the synthesis of essential coenzymes, enzymes or division factors so that the microbe can breakdown the nutrients in order to utilize them in the division process [18].

Table 1: Biomass of bacterial and fungal growth in DPH formulated media and LB or SDB media.

\begin{tabular}{|c|c|c|}
\hline Media and time & $\begin{array}{c}\text { Biomass in DPH } \\
\text { formulated media }(\mathrm{g} / \mathrm{l})\end{array}$ & $\begin{array}{c}\text { Biomass in } \\
\text { LB/SDB (g/l) }\end{array}$ \\
\hline \multicolumn{3}{|c|}{ Bacterial species } \\
\hline E. coli & 23.4 & 23.6 \\
\hline B. subtilis & 21.6 & 26.8 \\
\hline P. aeruginosa & 20.6 & 21.6 \\
\hline R. capsulatus & 10.4 & 9.6 \\
\hline \multicolumn{3}{|c|}{ Fungal species } \\
\hline M. anisopliae & 77.6 & 79.6 \\
\hline B. bassiana & 79.6 & 71.4 \\
\hline
\end{tabular}

Bacteria cultured in LB for $26 \mathrm{~h}$ and fungi in SDB for 21 days.

The log phase of bacterial growth was noted to have started $5 \mathrm{hrs}$ after inoculation and continued even after $26 \mathrm{hrs}$ of growth in the DPH-FM media. The growth of E. coli in the DPHFM media does not reach the stationary phase even after 26 hrs of growth, this could be as a result of abundance of nutrients in the media hence the bacteria continued to grow and divided equally. In the LB media the growth of $E$. coli through the log/exponential phase was noted to be very fast and only took 5 hrs for the bacteria to go through the log phase. After $10 \mathrm{hrs}$ of inoculation in the LB media, the bacterial growth seemed to enter the stationary phase as the growth curve plateaus but the growth curve does not reach the death phase indicating that there is equal death and growth of $E$. coli after $10 \mathrm{hrs}$ of growth and this continued for another $16 \mathrm{hrs}$. This could be due to the fact that the LB media nutrients are depleted. E. coli is noted to have slower growth than B. subtilis and $P$. aeruginosa in both media. On the other hand, E. coli growth is much faster than $R$. capsulatus in both media.

$B$. subtilis growth by biomass in DPH-FM media is noted at $21.6 \mathrm{~g} / \mathrm{l}$ and this is slightly lower than the biomass recorded in the growth of B. subtilis in LB media at $26.8 \mathrm{~g} / \mathrm{l}$ after $26 \mathrm{hrs}$ of growth (Table 1). For the growth of $B$. subtilis based on optical density the lag phase is achieved after $2 \mathrm{hrs}$ in both the DPH-FM and LB media (Figure 2). This is an indication that this bacteria does not take much time to adapt to the new environment in the media and also enzymes are activated faster than in $E$. coli with the bacteria taking up nutrients for its faster growth. The log phase begins $1 \mathrm{hr}$ after the lag phase and it continued for up to $10 \mathrm{hrs}$ after inoculation in both media. After the log phase the stationary phase was noted to begin $10 \mathrm{hrs}$ after inoculation in both media. The stationary phase continued even after $26 \mathrm{hrs}$ in DPH-FM media but in LB media it is noted that death phase began after 25 hrs of growth; again this could be due to depletion of nutrients in 
the LB media. The growth of B. subtilis in the LB and DPH-FM media was quite similar but the difference in biomass is an indication that generally the growth of this microbe is faster in LB media than in DPH-FM media.

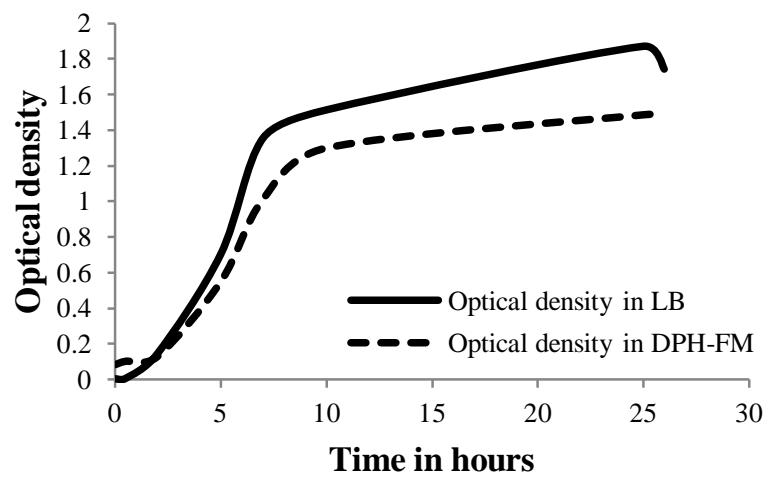

Fig. 2: Growth pattern of Bacillus subtilis in LB and DPH-FM media.

$P$. aeruginosa growth by biomass in DPH-FM media was noted at $20.6 \mathrm{~g} / \mathrm{l}$ and this is almost similar to the biomass recorded in the growth of $P$. aeruginosa in LB media at $21.6 \mathrm{~g} / \mathrm{l}$ after $26 \mathrm{hrs}$ of growth (Table 1). For the growth of $P$. aeruginosa based on optical density, the lag phase was achieved after 2 hours in both the DPH-FM and LB media indicating that this microbe adapts faster to its new environment than $E$. coli (Figure 3). The log phase begins $1.5 \mathrm{hrs}$ after the lag phase and it continues up to $10 \mathrm{hrs}$ after inoculation in both media. After the log phase the stationary phase is noted to begin $10 \mathrm{hrs}$ after inoculation in both media. The death phase begins after $25 \mathrm{hrs}$ of growth in both media. The growth of $P$. aeruginosa is almost similar to that of $B$. subtilis but slightly faster than that of $E$. coli in both media. However, in both media the growth of $P$. aeruginosa is much faster than that of $R$. capsulatus. It seems that for the growth of $P$. aeruginosa the nutrient content is used up faster in both media as death phase began at $26 \mathrm{hrs}$ of growth in both DPH-FM and LB

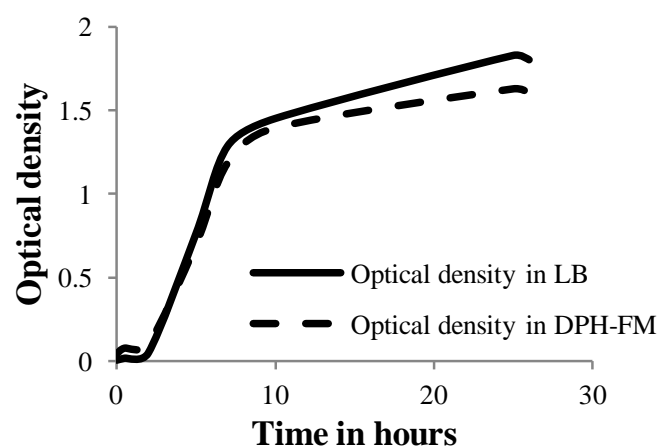

Fig. 3: Growth pattern of Pseudomonas aeruginosa in LB and DPH-FM media.

$R$. capsulatus growth by biomass in DPH-FM media was noted at $10.4 \mathrm{~g} / \mathrm{l}$ and this is almost similar but a little higher than the biomass recorded in the growth of $R$. capsulatus in LB media at $9.6 \mathrm{~g} / \mathrm{l}$ after $26 \mathrm{hrs}$ of growth (Table 1). For the growth of $R$. capsulatus based on optical density the lag phase was achieved after 2 hours in both the DPH-FM and LB media (Figure 4). The log phase began 5.5 hrs after the lag phase and it continued up to26hrs of growth. There is neither a stationary phase of growth noted nor a death phase in both media. This is an indication that $R$. capsulatus grows much slower than all the other three bacterial species. The nutrients are not depleted in both media at the end of $26 \mathrm{hrs}$ and hence the growth of organisms continued.

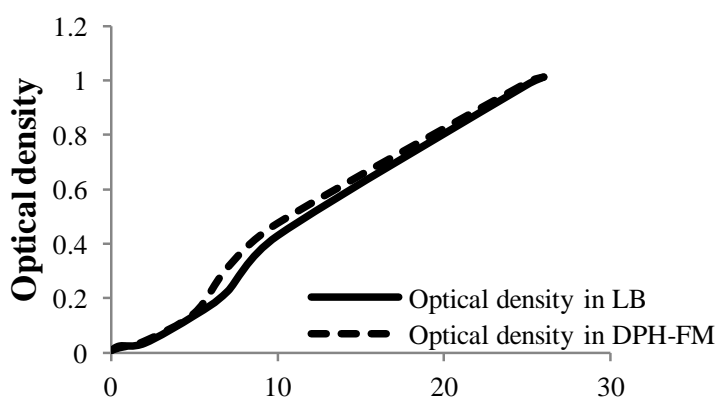

Time in hours

Fig. 4: Growth pattern of Rhodobacter capsulatus in LB and DPH-FM media.

M. anisopliae growth by biomass in DPH-Dextrose media was noted at $77.6 \mathrm{~g} / \mathrm{l}$ and this is almost similar but a little lower than the biomass recorded in the growth of $M$. anisopliae in SDB media at $79.6 \mathrm{~g} / \mathrm{l}$ after 21 days of growth (Table 1). For the growth of $M$. anisopliae by optical density, lag phase was achieved after 2 days and hence the initiation of growth was much slower as compared to that of bacteria which takes hours (Figure 5). The log phase then followed after the lag phase up to the $21^{\text {st }}$ day and the fungi seemed to continue growing as its growth curve does not indicate a stationary phase or a death phase.

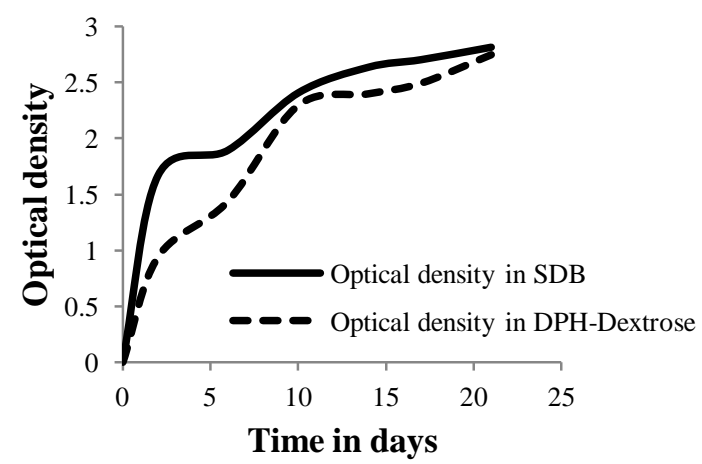

Fig. 5: Growth pattern of Metarhizium anisopliae in SDB and DPH-Dextrose media.

B. bassiana growth by biomass in DPH-Dextrose media was noted at $69.6 \mathrm{~g} / \mathrm{l}$ and this is lower than the biomass recorded in B. bassiana growth in SDB media at $71.4 \mathrm{~g} / \mathrm{l}$ after 21 days of growth (Table 1). For the growth of B. bassiana by optical density, lag phase was achieved after 2 days and hence the initiation of growth was much slower as compared to that of bacteria which took 30 minutes (Figure 6). The log phase then starts immediately after the lag phase and lasts up to the $6^{\text {th }}$ day of growth in both DPH-Dextrose and SDB media. After 6 days of growth the stationary phase began and lasted up to day 17 in both media. After 17 days of growth the B. bassiana entered the death phase 
for both media. Statistically, the growth of $M$. anisopliae as compared to that of $B$. bassiana in both media did not show any significant differences. However, according to the growth curves by biomass and optical density the growth of $M$. anisopliae did not reach the stationary phase while that of $B$. bassiana reached the death phase by the $17^{\text {th }}$ day (Figure 5 and 6). The $M$. anisopliae grew for longer periods and at a much slower rate than the $B$. bassiana in both the experimental and standard media.

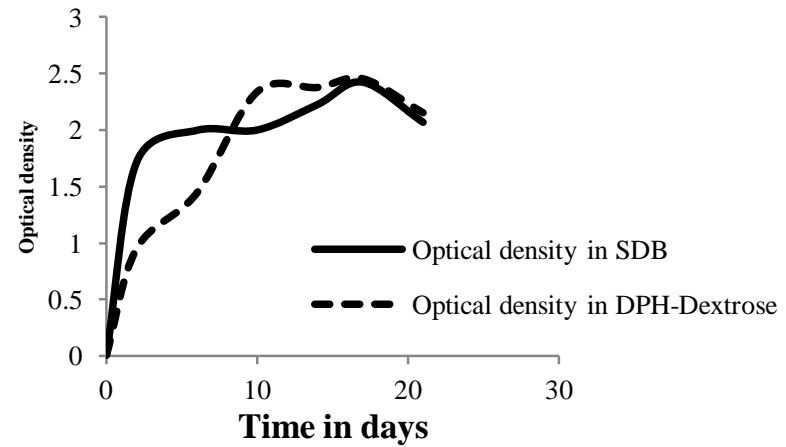

Fig. 6: Growth pattern of Beauveria bassiana in SDB and DPH-Dextrose media.

Results of bacterial growth estimation using biomass indicates that there is no significant difference $(p>0.05)$ in the growth of bacterial species studied in DPH-FM and in the standard LB media. Estimation of fungal growth using optical density reveals no significant difference $(p>0.05)$ in the growth of both fungi studied in DPH-Dextrose and in the standard SDB media.

The findings from this study concurs with previous investigations on the potential of fish protein hydrolysate from silver carp head peptone as microbial media which had no significant difference ( $p>0.05$ ) in growth of Vibrio anguillarum in comparison to the standard peptone media [7]. However, some protein hydrolysate obtained from the waste of silver carp filleting, yellow stripe trevally (Selaroides leptolepis) and yellow fin Tuna (Thunnus albacores) have shown better activity $(\mathrm{p}<0.05)$ as a formulated microbial media than the standard media used in those studies $[4,7,9]$.

\section{CONCLUSIONS}

DPH formulated media can be utilized to grow microbes such as bacteria and fungi effectively with supplementation to meet the nutritional demands of the specific microorganisms as it does not contain all macronutrients and micronutrients required for the proper growth of microbes. DPH provides the nitrogenous source in microbial media.

\section{ACKNOWLEDGEMENTS}

I wish to acknowledge the Department of Biochemistry, Department of Chemistry and Centre for Biotechnology and Bioinformatics, University of Nairobi, Nairobi, Kenya for the laboratory working space that they provided as well as the provision of reagents and equipment. I would also like to appreciate Jomo Kenyatta University of Agriculture and Technology, Nairobi, Kenya for providing the microorganisms, $E$. coli, B. subtilis, P. aeruginosa, R. capsulatus, M. anisopliae and B. bassiana needed to complete this work.

\section{Financial support and sponsorship: Nil.}

Conflict of Interests: There are no conflicts of interest.

\section{REFERENCES}

1. Nair AJ. Introduction to Biotechnology and Genetic Engineering. In Introduction to Biotechnology and Genetic Engineering. Infinity Science Press Llc. 2008 P. 689-699.

2. Asimov SI, Horn SJ, Eosin VGH.Use of hydrolysates from Atlantic cod (Gadusmorhua L.) viscera as a complex nitrogen source for lactic acid bacteria. FEMS Microbiol. Letters.2005; 248(1), 65-68.

3. Martone CB, Pérez BorlaO, Sánchez J J. Fishery by-product as a nutrient source for bacteria and archaea growth media. Biores. $\begin{array}{lllll}\text { Technol. J.2005; } & 96 & \text { (3), } & \text { 383-7. }\end{array}$ http://doi.org/10.1016/j.biortech.2004.04.008

4. Ovissipour M, Safari R, Motamedzadegan A, Rasco B, Pourgholam R, Mohagheghi E, Molla AE. Use of hydrolysates from yellow fin tuna Thunnus albacares fisheries by-product as a nitrogen source for bacteria growth media. Internat. Aquatic Res. 2009; 1(1), 73-77.

5. Olivieri, R., Sabbatini, F., Kontakou, M., Tagliaferri, L., Giglioli, A., \&Rappuoli, R. (2016). U.S. Patent No. 9,284,526. Washington, DC: U.S. Patent and Trademark Office.

6. Beaulieu L, Desbiens M, Thibodeau J,Thibault S. Pelagic fish hydrolysates as peptones for bacterial culture media. Can. J.Microbiol. 2009; 55(11), 1240-1249.

7. Safari R, Nasrollahzadeh Saravi H, Pourgholam R, Motalebi AA, Ghoroghi A. Use of Hydrolysates from Silver Carp (Hypophthalmichthys molitrix) Head as Peptone for Vibrio anguillarum and Optimization Using Response Surface Method (RSM). J.Aquatic Food Product Technol. 2011;20 (2), 247-257. http://doi.org/10.1080/10498850.2011.562064

8. Fallah M, BahramS, Javadian SR.Fish peptone development using enzymatic hydrolysis of silver carp by-products as a nitrogen source in Staphylococcus aureus media. Food Sci. Nutrit. 2015;3 (2), 1-5. $\mathrm{http}: / /$ doi.org/10.1002/fsn3.198

9. Shu G, Zhang Q, Chen H, Wan H, Li H. Effect of Five Proteases Including Alcalase, Flavourzyme, Papain, Proteinase K And Trypsin On Antioxidative Activities Of Casein Hydrolysate From Goat Milk. Acta Universitatis Cibiniensis. Series E: Food Technology, 2015; 19 (2), 65-74.

10. Klompong V, Benjakul S, Kantachote D,Shahidi F. Characteristics and use of yellow stripe trevally hydrolysate as culture media. $J$. Food Sci.2009; 74(6), 219-225.

11. Nyeko D. Challenges in sharing of Lake Victoria Fisheries Resources: Policies, Institutions and Processes. LVFO Regional Stakeholder's Conference Kampala. Sponsored by LVFO, European Union and CTZ, 2008.

12. SaleheM, Mlaponi E, Onyango PO, Mrosso Hilary DJ. Contribution of Lake Victoria Dagaa fishery in East and Central African fish trade. 16th IIFET Conference, July 16-20, 2012, Dar es Salaam, Tanzania

13. Owaga EE, Onyango CA, Njoroge KA. Influence of selected washing treatments and drying temperatures on proximate composition of dagaa (Rastrineobola argentea), a small pelagic fish species. Afr. J. Food Agric. Nutrit. Dev. 2010; 10, (7).

\section{How to cite this article:}

Pere K, Mbatia BN, Muge E, Wekesa VW. Dagaa (Rastrinoebola argentea) protein hydrolysate as a nitrogen source in microbial culture media. J App Biol Biotech. 2017; 5 (03): 008-012. 